\title{
Modification of Polyoxymethylene for Increased Thermal Resistance
}

\author{
Remo Merijs Meri , (D) ${ }^{1}$ Janis Zicans, ${ }^{1}$ Agnese Abele, $\quad{ }^{1}$ Tatjana Ivanova, ${ }^{1}$ Martin,s Kalnin,s, ${ }^{1}$ Karlis Kundzin, $s^{2}$ \\ ${ }^{1}$ Institute of Polymer Materials, Faculty of Materials Science and Applied Chemistry, Riga Technical University, \\ Riga, Latvia \\ ${ }^{2}$ Institute of Solid State Physics, University of Latvia, Riga, Latvia
}

Ternary nanocomposites, composed of polyoxymethylene (POM), ethylene octene copolymer and zinc oxide ( $\mathrm{ZnO})$, are prepared by melt compounding. The effects of two types of ethylene-octene copolymers, differing with a-octene content (38\% for EOC38 and 17\% for EOC17), as well as nanostructured $\mathrm{ZnO}$ on thermal behavior of POM are investigated. The content of EOC in the POM based composites is varied between 10 and $50 \mathrm{wt} \%$, while the content of $\mathrm{ZnO}$ is $2 \mathrm{wt} \%$. Thermal behavior of POM based systems are studied by using differential scanning calo-rimetry and thermogravimetric analysis coupled with Fou-rier transform infrared spectroscopy. Results of thermogravimetric analysis show that, by rising either the elastomer or $\mathrm{ZnO}$ content, thermal stability of the investi-gated POM composites can be increased. The modifying effect of EOC17 in respect of thermal resistance is some-what greater than that of EOC38. Simultaneous addition of EOC and $\mathrm{ZnO}$ to POM is synergistic with respect to thermal stability of the composite material.

\section{INTRODUCTION}

Development of the composites as perspective substitutes of traditional materials becomes increasingly popular in new material design. Over the last years polymer nanocomposites have attracted much interest because addition of small amount of nanosized fillers can yield considerable property increment, unachievable by using traditional micron-sized fillers. In literature there are many researches about neat polymer and inorganic filler composites and nanocomposites but considerably less effort is devoted to the development of polymer blend nanocom-posites. By conducting simple data search in Scopus electronic data base there are at least 160 (at this number is continuously growing) review articles on polymer nanocomposites since 2000 , while the first review article on polymer blend nanocom-posites appeared only in 2015 [1].

Polyoxymethylene (POM) is one of the most important engineering polymers, experiencing increased demand due to open-ing up of new markets and applications [2]. It provides high surface hardness, low wear and friction, and high resistance to chemicals such as alcohols, aldehydes, esters and glycols.

Correspondence to: R. Merijs-Meri; e-mail: remo.merijs-meri@rtu.lv Contract grant sponsor: National Research Program MultIfunctional Materi-als and composItes, photonicS and nanotechnology (IMIS ${ }^{2}$ ).
Common applications of POM are medical devices, automotive components, water and gas tubing systems, household equipment. However, at high temperatures formaldehyde and formic acid are released from POM because of unstable methyl oxide bonds in its macromolecular structure [3-7]. Consequently, improved thermal resistance of POM is an important issue to broaden application possibilities of the polymer. Various approaches have been used to increase thermal stability of POM, i.e., modification with (1) organic compounds, containing active $\mathrm{H}$ atom, such as crosslinked melamine-formaldehyde polycondensate, acting as formaldehyde absorbent by the addition reaction of the hydrogen on the amine groups of its molecules with formaldehyde produced by decomposition of POM [8], (2) low-molecular organic compounds, for instance bisphenol-A and amine to form in situ benzoxazines via the Mannich reaction, allowing control of formaldehyde generation [9], (3) high molecular compounds with higher thermal stability than POM itself, for instance acrylonitrile-butadiene-styrene copolymer, acting also as toughening agent [10], (4) noncom-bustible inorganic minerals like bentonite [11], montmorillonite clay [12], zinc oxide ( $\mathrm{ZnO})$ [13], titanium dioxide [14] acting as impermeable heat resistant barriers. Although it is known that simultaneous use of various additives can synergistically influence properties of the composite materials, only few attempts have been made to investigate combined effects of previously proven organic and inorganic compounds to increase thermal stability of POM. On this score, it has been shown that [10] addition of nanoclay to POM blend with $25 \mathrm{wt} \%$ of acrylonitrilebutadiene-styrene copolymer thermal stability of the material is further increased. Consequently, it is interesting to extend this research direction by modifying POM with both noncombustible $\mathrm{ZnO}$ and ethylene-octene copolymer, having higher thermal stability than POM in addition to toughening capacity.

\section{EXPERIMENTAL}

\section{Materials}

Polyoxymethylene copolymer (POM: Kocetal 900, Kolon Plastics Inc.) is used as a matrix. Two types of ethylene-octene copolymers with distinct a-octene contents (Engage 8540 (octene co-monomer content-17\%), EOC17, and Engage 8200 (octene co-monomer content-38\%), EOC38, The Dow Chemical Company) are used as toughening agents as well as thermal stabilizers. More detailed characteristics of POM, EOC17 and EOC38 are given in the Table 1.

Nanostructured $\mathrm{ZnO}$ filler (purity of $99.7 \%$ ) in the form of tetrapod-shaped particles with arm lengths of 20-100 $\mathrm{nm}$ and average diameters of $20 \mathrm{~nm}$ is synthesized in the Institute of Inorganic Chemistry of Riga Technical University. 
TABLE 1. Characterization of used polymers.

\begin{tabular}{|c|c|c|c|c|}
\hline & $\begin{array}{l}\text { Maximum melting temperature } \\
\qquad(8 \mathrm{C})\end{array}$ & $\begin{array}{c}\text { Crystallinity degree } \\
\qquad(\%)\end{array}$ & $\begin{array}{l}\text { Density } \\
\left(\mathrm{g} \mathrm{cm}^{23}\right)\end{array}$ & $\begin{array}{l}\text { Melt flow index } \\
\left(\mathrm{g} 10 \mathrm{~min}^{21}\right)\end{array}$ \\
\hline POM & 166 & 60 & 1.41 & 42 \\
\hline EOC 38 & 60 & 14 & 0.87 & 5 \\
\hline EOC17 & 100 & 17 & 0.9 & 1 \\
\hline
\end{tabular}

POM composites with various EOC $(0,10,30,50 \mathrm{wt} \%)$ and $\mathrm{ZnO}$ ( 0 and $2 \mathrm{wt} \%$ ) contents are prepared at $1708 \mathrm{C}$ by using two roll mills LRM-S-110/3E (LabTech Engineering Company Ltd). Compounding is performed in following steps. Initially POM and its blends with ethylene-octene copolymers are proc-essed until the development of uniform film of the melted poly-mer on the hot roll (the procedure in average takes no more than a minute). Subsequently $\mathrm{ZnO}$ is gradually added and mix-ing is continued for $7 \mathrm{~min}$.

Characterization. Differential scanning calorimetry (DSC) is performed by using DSC1/200W apparatus (Mettler Toledo). All measurements are made under $\mathrm{N}_{2}$ flow. Samples of about $10 \mathrm{mg}$ are heated from $21008 \mathrm{C}$ up to $2008 \mathrm{C}$ with a heating rate of $108 \mathrm{C}$ $\min ^{21}$. Results of the second heating run are analyzed to erase thermal history of the sample.

Mettler/Toledo TG1/SF thermogravimetric analyzer coupled with ThermoFischer Nicolet 6700 FTIR spectrometer (TG coupled FTIR) is used for determination of thermal stability of the investigated multi-phase systems. Samples of about $10 \mathrm{mg}$ are heated under $\mathrm{N}_{2}$ flow from $258 \mathrm{C}$ to $6008 \mathrm{C}$ with a heating rate of $108 \mathrm{C} \min ^{21}$. FTIR spectrum is recorded every $6 \mathrm{~s}$.

Scanning electron microscope (SEM) SEM-FIB Tescan Lyra with Schottky field emission cathode is used to study the morphology of the freeze fracture surfaces of the specimens of POM/EOC blends and it nanocomposites. All specimens are coated with gold by using Quorum Q15OR ES sputter coater under argon flow for $30 \mathrm{~s}$.

\section{RESULTS AND DISCUSSION}

By considering that properties of multicomponent materials greatly depend on distribution of dispersed phase within continuous matrix, morphology of freeze fracture surfaces of the specimens of POM, EOC, it blends and nanocomposites are initially investigated. As demonstrated in Fig. 1, fracture sur-face of POM (Fig. 1a) is characterized by a considerable roughness, which is typical for highly crystalline polymers. In the same time surface morphology of EOC38 (Fig. 1b), simi-larly to EOC17, is much smoother and contains short wormlike crystalline domains. Fracture morphologies of the POM/EOC blends are typical for two-phase systems and are characterized with spherical domains of EOC in the POM matrix. Particle sizes of the elastomer phase increases along with raising its content. Sizes of EOC38 particles, however, are smaller in comparison to those of EOC17, most probably because of higher difference between the melt viscosities of POM and EOC17 (as shown in Table 1). For an example, average size of the elastomer particle in the POM composite with $10 \mathrm{wt} \%$ of EOC is 2.8 and $5.7 \mathrm{~lm}$ for EOC 38 and EOC17 respectively. Characteristic micrographs, revealing distribution of $\mathrm{ZnO}$ tetrapod shaped particles within the polymer blend matrix, are shown in Fig. 1c and d for the case of POM blend with 10 wt $\%$ of EOC and $2 \mathrm{wt} \%$ of $\mathrm{ZnO}$.

Calorimetric properties of POM, EOC38, EOC17, as well as their blends and nanocomposites with $\mathrm{ZnO}$ are investigated, as it is well known that thermal destruction mainly occurs in the amorphous phases of the polymers. The effects of EOC and $\mathrm{ZnO}$ on the crystallinity of the investigated POM based blends and nanocomposites are shown in Table 2. Crystallinity of the investigated blends gradually decreases along with addition of EOC. Besides it experimentally detected total crystallinity val-ues are lower than those calculated according to the rule of the mixtures, whereas smaller deviations are observed for the blends with EOC38, as a consequence of more favorable mixing conditions due to closer values of melt flow indices of these polymer constituents. In the Table 2 crystallinities of POM and EOC phases in the blends are also shown. Crystallinities of POM and EOC phases in the blends are calculated from the calorimetric data by considering weight contents of the individual polymeric components as well as by assuming that melting enthalpies of $100 \%$ crystalline material is 290 and $250 \mathrm{Jg}^{21}$ for EOCs and POM respectively. In comparison to the neat polymers, crystal-linities of POM and EOC in the blends are lower, testifying that both components hinder each other's crystallization. By evaluat-ing the effect of $\mathrm{ZnO}$ content on the crystallinity degrees of POM, EOC38 and EOC17 no significant changes have been observed.

Thermogravimetric curves of POM, EOC38 and EOC17 are compared in Fig. 2. Thermal degradation of these polymers in an inert environment is attributed to the radical random scission mechanism. Thermal degradation of POM macromolecule is initiated directly in the main chain by the scission of the $-\mathrm{CH}_{2}-\mathrm{O}$ linkages, which are the weakest points in the polymer macromolecule [5]. In EOC macromolecule the weakest points are tertiary carbon atoms, at which breakage of the side-chains generally occurs [15]. Hence, it is logical that degradation process of EOC is slower than that of POM and that, degradation process of EOC 17 is slower than that of EOC 38, while the former elastomer contains smaller amount of tertiary carbon atoms in the macromolecular chain.

Consequently, addition of the either of the elastomers to POM raise thermal resistance of the material (Fig. 3a and c). First derivative of the weight loss curves (Fig. 3b and d) clearly show that multiple processes occur during degradation. The first peak is generally attributed to decomposition of POM, while the other one-to degradation of EOC. Such behavior is characteristic for heterogeneous two-component blends. According to Fig. $3 \mathrm{~b}$ and $\mathrm{d}$, onset of thermal destruction of POM phase in the blends starts later in comparison to neat POM, while thermal 


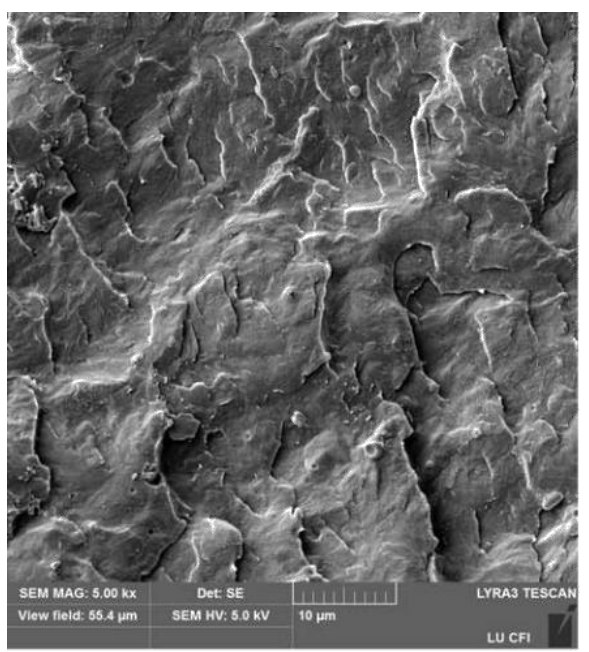

a

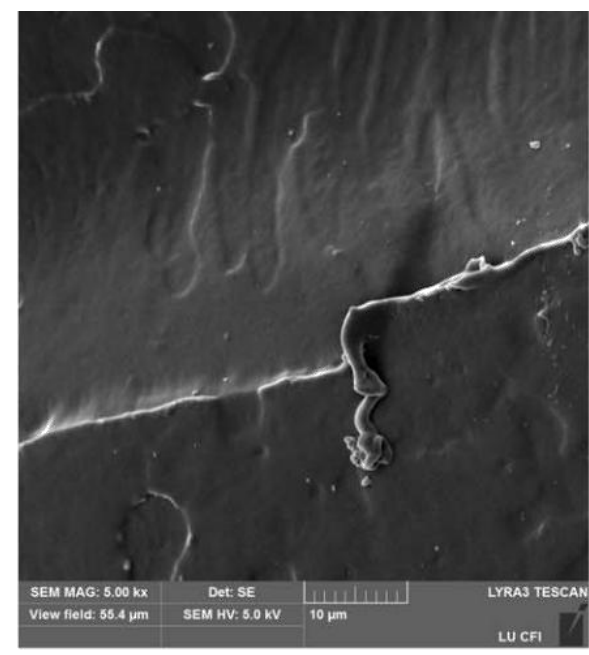

b

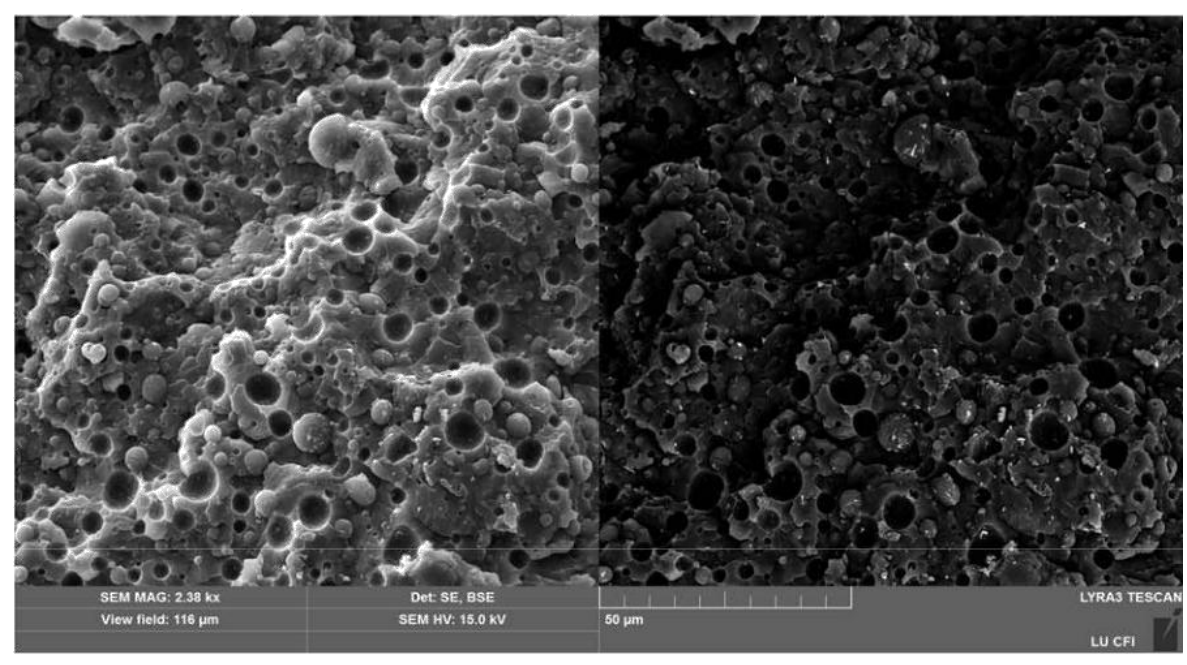

c

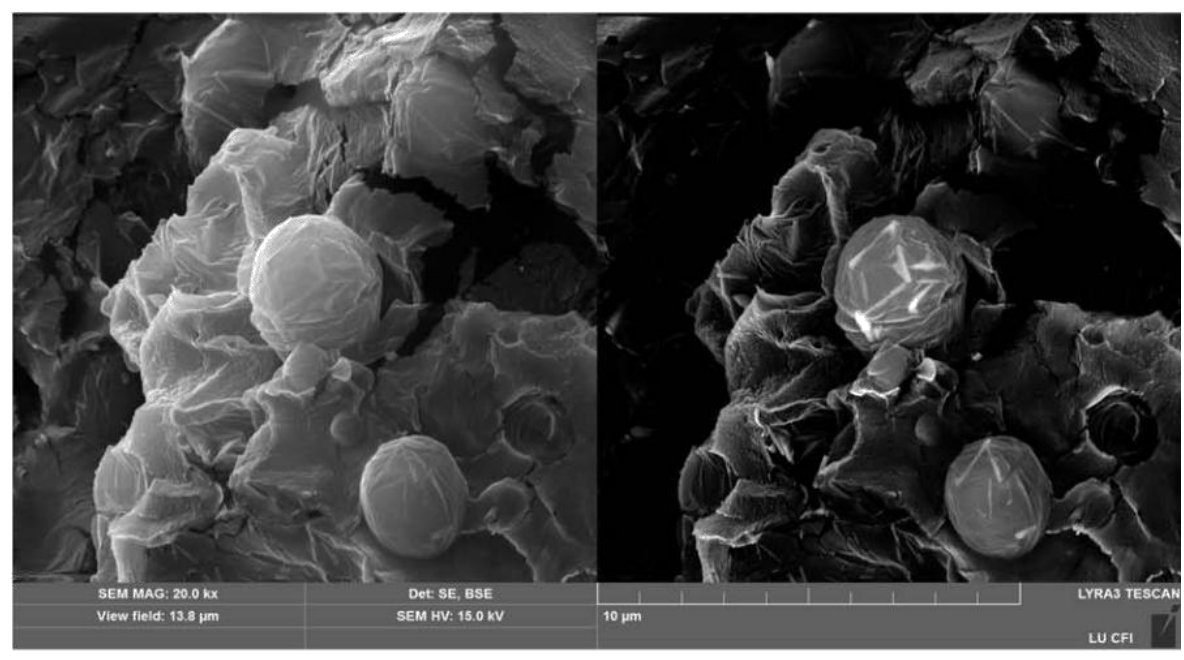

d

FIG. 1. SEM micrographs of freeze fracture surfaces of the specimens of POM (a), EOC38 (b) and POM nanocomposite with $10 \mathrm{wt} \%$ of EOC38 and $2 \mathrm{wt} \%$ of $\mathrm{ZnO}$ at different magnifications: $2.38 \mathrm{kx}$ (c) and $20.0 \mathrm{kx}(\mathrm{d})$. 
TABLE 2. Crystallinity degrees of POM-based blends and nanocomposites.

\begin{tabular}{|c|c|c|c|c|c|c|}
\hline $\begin{array}{l}\text { POM } \\
(\mathrm{wt} \%)\end{array}$ & $\begin{array}{c}\text { Crystallinity degree of } \\
\text { EOC } 38 \text { phase }(\%)\end{array}$ & $\begin{array}{l}\text { Crystallinity degree } \\
\text { of POM phase }(\%)\end{array}$ & $\begin{array}{c}\text { Total crystallinity degree } \\
\text { of the composite }(\%)\end{array}$ & $\begin{array}{l}\text { Crystallinity degree } \\
\text { of EOC } 17 \text { phase }(\%)\end{array}$ & $\begin{array}{l}\text { Crystallinity degree } \\
\text { of POM phase }(\%)\end{array}$ & $\begin{array}{c}\text { Total crystallinity degree } \\
\text { of the composite }(\%)\end{array}$ \\
\hline & \multicolumn{3}{|l|}{ POM/EOC38 blends } & \multicolumn{3}{|l|}{ POM/EOC17 blends } \\
\hline 100 & & 70 & $70(70)^{* *}$ & & 70 & $70(70)^{* *}$ \\
\hline 90 & 3 & 69 & $62(64)^{* *}$ & 17 & 60 & $56(66)^{* *}$ \\
\hline 70 & 4 & 68 & $49(53)^{* *}$ & 22 & 58 & $47(59) * *$ \\
\hline 50 & 8 & 64 & $36(41)^{* *}$ & 26 & 57 & $42(52)^{* *}$ \\
\hline \multirow[t]{2}{*}{0} & 12 & & $12(12)^{* *}$ & 34 & & $34(34) * *$ \\
\hline & \multicolumn{3}{|c|}{ POM/EOC 38 blends with 22 wt $\% \mathrm{ZnO}$} & \multicolumn{3}{|c|}{ POM/EOC 17 blends with $22 \mathrm{wt} \% \mathrm{ZnO}$} \\
\hline 100 & & 71 & 71 & & 71 & 71 \\
\hline 90 & $*$ & 64 & 56 & 17 & 69 & 63 \\
\hline 70 & 1 & 72 & 50 & 25 & 54 & 44 \\
\hline 50 & 11 & 40 & 25 & 29 & 59 & 43 \\
\hline 0 & 12 & & 12 & 35 & & 35 \\
\hline
\end{tabular}

*Not observed; **In brackets calculated crystallinity degree is shown.

destruction of EOC phase ends faster in comparison to neat EOC, leading to the conclusion that thermal destruction of the composites occurs in a narrower temperature diapason.

The effect of EOC on the percentage weight loss of POM matrix composites is shown in Table 3. Data represented in the Table 3 confirm that addition of EOC allows increase thermal stability of POM in a whole diapason of the investigated temperatures. By analyzing the effect of addition of $2 \mathrm{wt} \%$ of $\mathrm{ZnO}$ on thermal behavior of the investigated POM blends with EOC38 and $\mathrm{EOC} 17$, it can be concluded that in general $\mathrm{ZnO}$ positively affects percentage weight loss temperatures. Evidently this is because of $\mathrm{ZnO}$ nanoparticles, acting as effective barriers, preventing gas exchange during pyrolysis. It can be also concluded that before destruction of POM phase (until ca. 4008C) somewhat higher thermally stabilizing effect is observed for EOC38 containing systems, while at higher temperatures, when POM matrix is partially or completely degraded, the thermal destruction behavior is increasingly influenced by thermal resistance of the remaining elastomer phase, which is somewhat higher for EOC17, as it was discussed above.

To identify the evolved volatile products during degradation of the investigated compositions, TG coupled FTIR has been used. The data are analyzed in three weight loss regions: first-

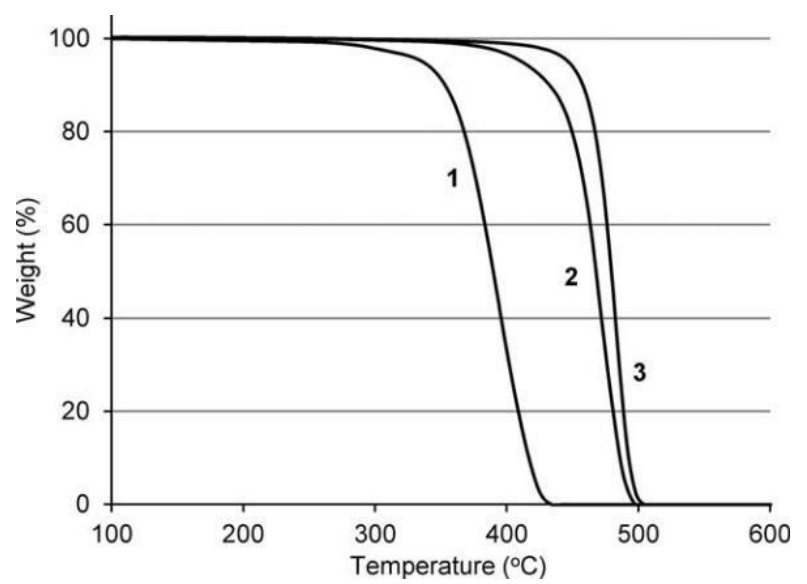

FIG. 2. Thermogravimetric curves of POM (1), EOC38 (2), and EOC17 (3). attributed to the processes until onset of degradation (2808C [26 min]); Second-attributed to the processes during thermal destruction of POM phase (4348C [41 min]); and third-attributed to the processes of thermal destruction of EOC phase (4208C-5108C [40-49 min]). Until degradation onset temperature there is gradual minor weight loss, being somewhat larger for POM in comparison to the elastomers (0.7\% vs. $0.4 \%)$. Evi-dently this weight loss is attributed to water and other volatiles (such as formaldehyde in the case of POM) in the initial poly-mers. Appearance of absorption peaks at 1,630 and $3,400 \mathrm{~cm}^{21}$ (attributed to release of water), as well as at 2,800 and $1,755 \mathrm{~cm}^{21}$ (attributed to release of formaldehyde) after ca. $26 \mathrm{~min}$ of thermal exposure confirm this assumption. Appearance of the formaldehyde peak already at the beginning of destruction process proves that POM has a tendency to split off formalde-hyde starting at unstable chain-ends. By increasing thermal exposure time up to ca. $40 \mathrm{~min}$, which corresponds to ca. $4208 \mathrm{C}$, intensity of the formaldehyde peaks at 2,800 and $1,755 \mathrm{~cm}^{21}$ increase testifying that the amount of evolved form-aldehyde rapidly increases. Part of the evolved gases from POM could be attributed also to methyl formate as confirmed by appearance of a shoulder at 2,900-3,000 $\mathrm{cm}^{21}$, as well as absorption peaks at 1,773-1,714, 1,450 , and $1,209 \mathrm{~cm}^{21}$. Simi-larly, formation of methyl alcohol among the evolved gases is possible as it is supported by appearance of the corresponding peaks at 1,000-1,100, 1,3001,400 , and $3,680-3,712 \mathrm{~cm}^{21}$ in the TG coupled FTIR spectrum. It should, however, be men-tioned that analysis of the evolved gas species is disturbed by overlapping of the spectra. In addition to previously mentioned gases, certain amounts of $\mathrm{CO}_{2}$ and $\mathrm{CO}$ (at 2,392, 2,313, and 2,240-2,021 $\mathrm{cm}^{21}$, respectively for $\mathrm{CO}_{2}$ and $\mathrm{CO})$ are evolved throughout the thermal destruction of POM. $\mathrm{CO}_{2}$ and $\mathrm{CO}$ accompanies also destruction of EOC17 and EOC38. In the main destruction region of EOC17 and EOC38 characteristic peaks of polyethylene decomposition are observed at 3,084, 2,929, 2,850, 1,759-1,491, 1,457, 998-911, and $720 \mathrm{~cm}^{21}$. These peaks are attributed to ethylene and higher oligomers (propylene, butene, pentene, hexene as well as a series of alka-nes), which arise from hydrogen transfer to different positions along the polymer chain [16]. There are practically no differ-ences in the evolved gases for EOC38 and EOC17. 


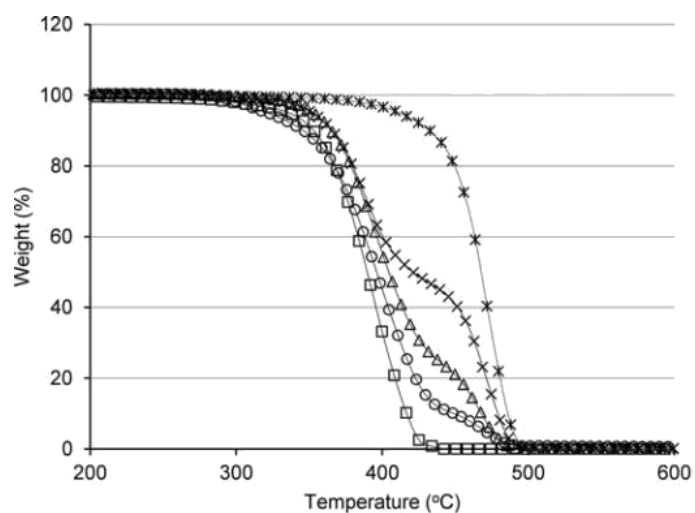

a

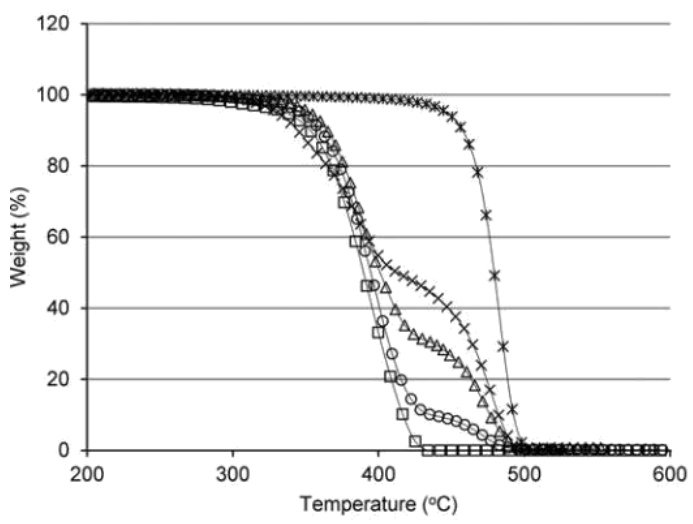

C

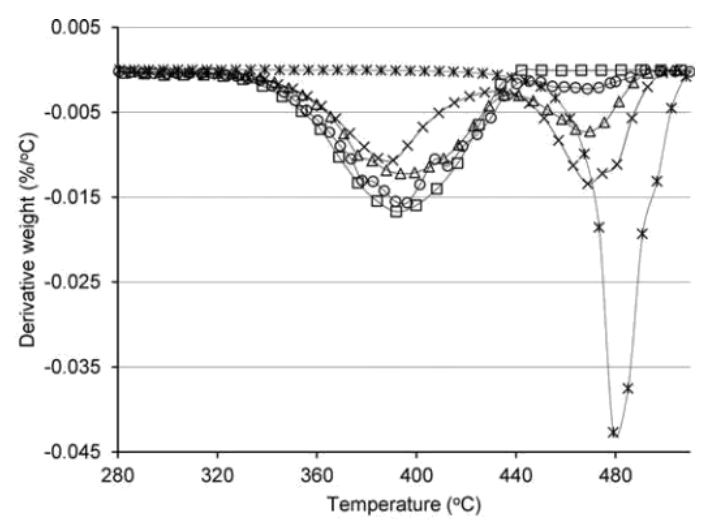

b

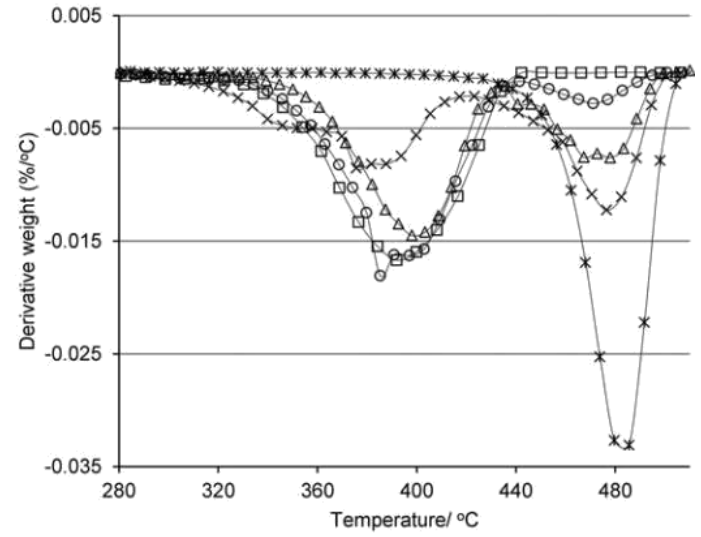

d

FIG. 3. Thermogravimetric curves and first derivatives of the weight loss curves of POM, EOC and their binary blends: POM/EOC38 (a, b) and POM/EOC17 (c, d) (POM ( ); POM 110 wt\% of EOC ( ); POM 130 wt\% of EOC (D); POM $150 \mathrm{wt} \%$ of $\operatorname{EOC}(\mathrm{x}) ; \mathrm{EOC}(;))$.

TABLE 3. Characteristic degradation temperatures (8C) of ZnO-modified POM/EOC blends at selected values of percentage weight losses.

\begin{tabular}{|c|c|c|c|c|c|c|c|}
\hline POM (wt\%) & $5 \%$ wt loss & $10 \%$ wt loss & $20 \%$ wt loss & $40 \%$ wt loss & $50 \%$ wt loss & $60 \%$ wt loss & $80 \%$ wt loss \\
\hline & \multicolumn{7}{|c|}{ POM/EOC38 } \\
\hline 100 & 324 & 345 & 369 & 381 & 387 & 392 & 403 \\
\hline 90 & 311 & 347 & 368 & 387 & 394 & 400 & 417 \\
\hline 70 & 347 & 366 & 379 & 399 & 408 & 417 & 455 \\
\hline 50 & 344 & 366 & 380 & 400 & 421 & 452 & 471 \\
\hline 0 & 402 & 434 & 450 & 465 & 468 & 472 & 477 \\
\hline \multicolumn{8}{|c|}{ POM/EOC38/22 wt\% ZnO } \\
\hline 100 & 342 & 358 & 378 & 387 & 393 & 398 & 409 \\
\hline 90 & 345 & 365 & 378 & 389 & 395 & 401 & 415 \\
\hline 70 & 353 & 365 & 376 & 391 & 399 & 407 & 453 \\
\hline 50 & 363 & 381 & 394 & 429 & 448 & 457 & 470 \\
\hline 0 & 431 & 449 & 459 & 465 & 467 & 470 & 477 \\
\hline \multicolumn{8}{|c|}{ POM/EOC17 } \\
\hline 100 & 324 & 345 & 369 & 381 & 387 & 392 & 403 \\
\hline 90 & 346 & 357 & 374 & 386 & 397 & 398 & 411 \\
\hline 70 & 311 & 317 & 330 & 392 & 398 & 411 & 464 \\
\hline 50 & 334 & 346 & 364 & 400 & 411 & 455 & 471 \\
\hline 0 & 445 & 456 & 468 & 473 & 480 & 482 & 490 \\
\hline \multicolumn{8}{|c|}{ POM/EOC17/22 wt\% ZnO } \\
\hline 100 & 342 & 358 & 378 & 387 & 393 & 398 & 409 \\
\hline 90 & 346 & 358 & 369 & 385 & 391 & 397 & 412 \\
\hline 70 & 353 & 365 & 382 & 391 & 405 & 405 & 461 \\
\hline 50 & 353 & 371 & 388 & 410 & 442 & 459 & 478 \\
\hline 0 & 453 & 459 & 470 & 474 & 482 & 483 & 492 \\
\hline
\end{tabular}



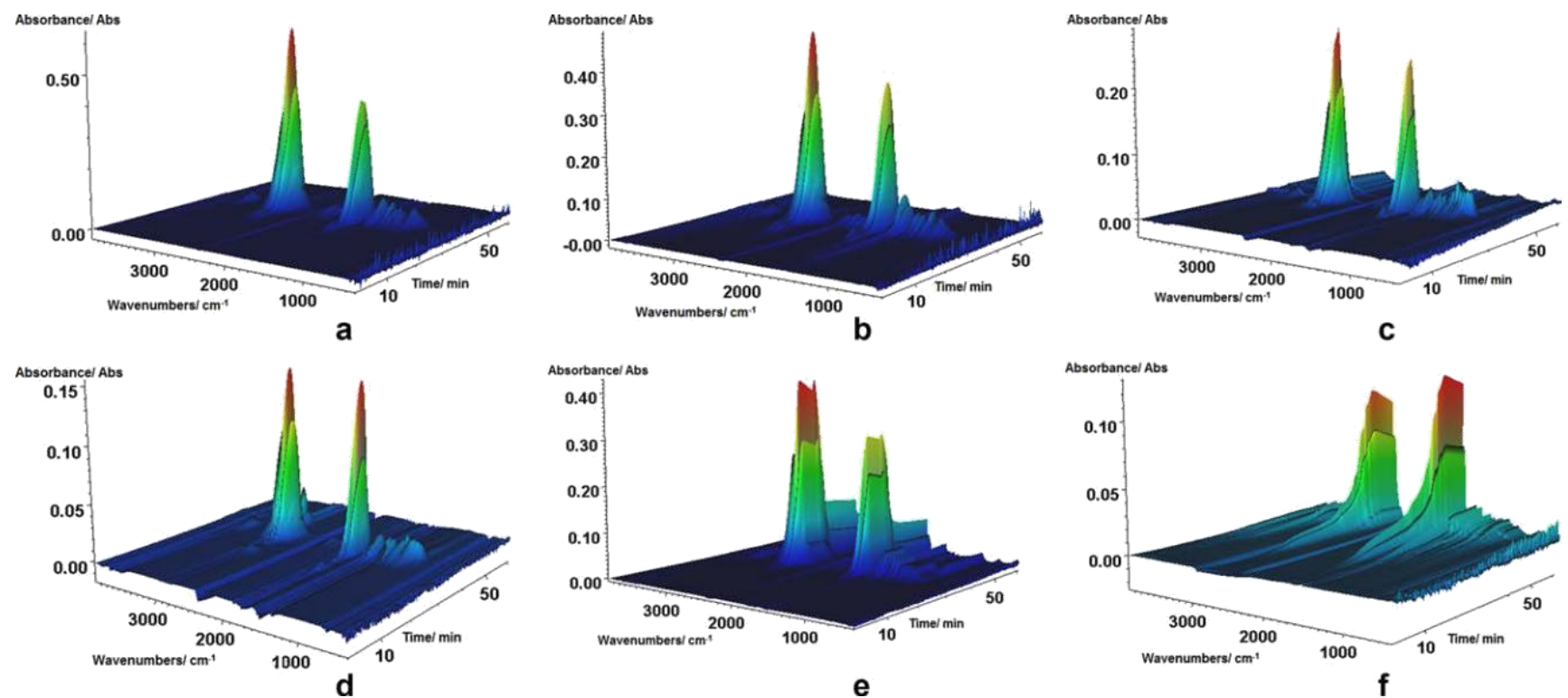

FIG. 4. TG-FTIR spectra of POM, POM/EOC17 blends and ZnO containing nanocomposites: (a) POM; (b) POM 12 wt $\%$ of $\mathrm{ZnO}$; (c) POM 110 wt\% of EOC17; (d) POM 110 wt\% of EOC17 12 wt\% of ZnO; (e) POM 150 wt $\%$ of EOC17; (f) POM $150 \mathrm{wt} \%$ of EOC17 $12 \mathrm{wt} \%$ of ZnO. [Color figure can be viewed at wileyon-linelibrary.com]

Representative graphs, describing the effect of the addition of EOC and $\mathrm{ZnO}$ on the spectrum of the evolved gases due to thermal decomposition of the investigated POM based systems are shown in the Fig. 4. In general, by introduction of EOC to

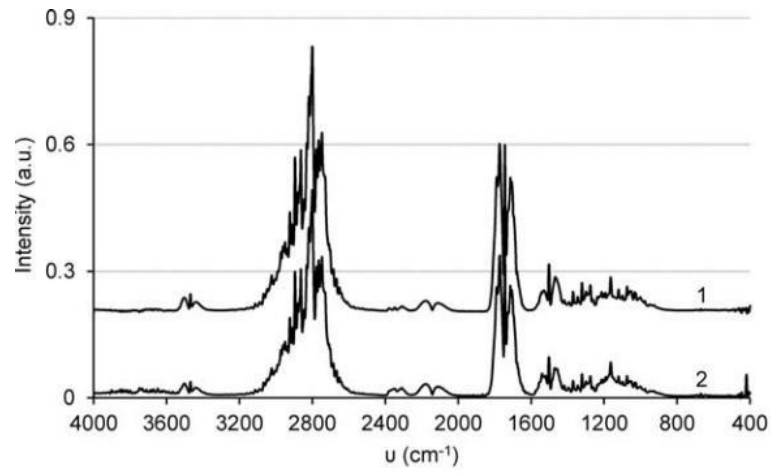

POM, characteristic peaks of destruction products of EOC are observed in the FTIR spectra of POM based blends in the temperature region of the destruction of the elastomer phase. The intensities of the characteristic peaks of EOC change in

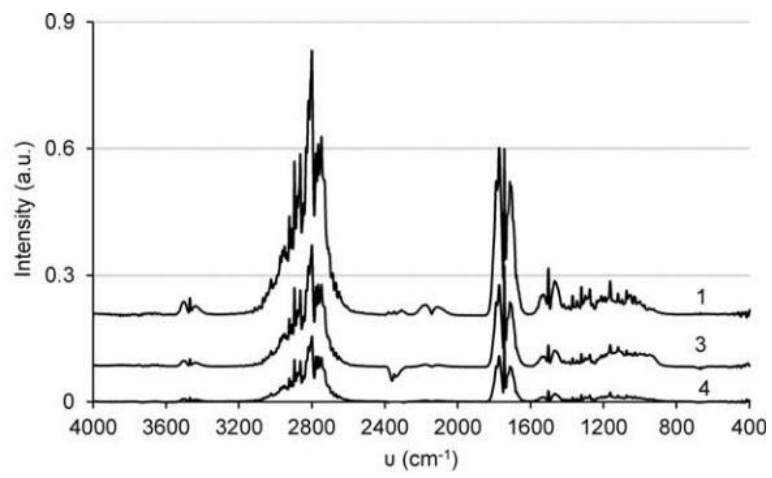

b

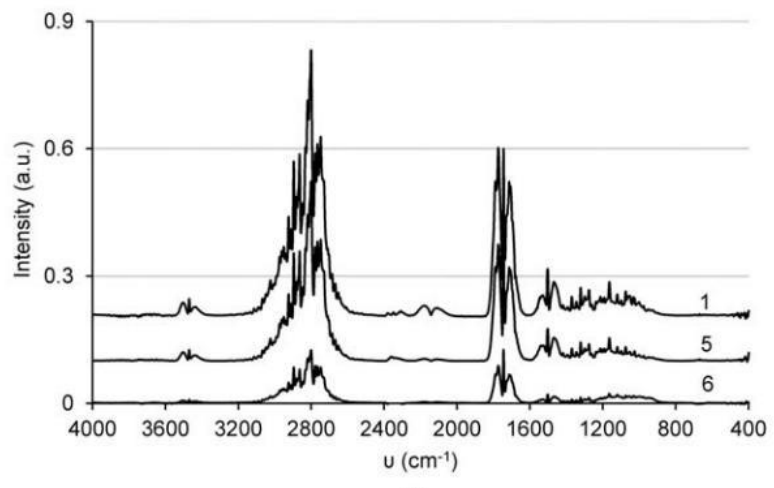

c

FIG. 5. Representative FTIR spectra of the evolved gases in the second weight loss region for POM (1), POM 12 wt\% of $\mathrm{ZnO}$ (2), POM $110 \mathrm{wt} \%$ of EOC17 (3), POM $110 \mathrm{wt} \%$ of EOC17 $12 \mathrm{wt} \%$ of ZnO (4), POM $150 \mathrm{wt} \%$ of EOC17 (5) and POM $150 \mathrm{wt} \%$ of EOC17 $12 \mathrm{wt} \%$ of $\mathrm{ZnO}$. 
accordance with the elastomer content in the blends. The effect of $\mathrm{ZnO}$ on the evolved gases from POM, EOC17, EOC38 and their binary blends cannot be not clearly defined, largely due to overlapping of thermal destruction events.

By considering that main weight losses of the investigated systems are observed in the destruction region of POM phase, comparative FT-IR spectra of the evolved gases at second weight loss region more in detail are shown in Fig. 5. Accord-ingly, addition of $\mathrm{ZnO}$ to $\mathrm{POM}$ causes certain decrement in the intensities of the evolved gases, mainly formaldehyde. In the case of EOC containing systems, peak intensities, attributed to formaldehyde, are also decreased. Further decrease of the formaldehyde peaks is observed upon introduction of $2 \mathrm{wt} \%$ of $\mathrm{ZnO}$ into the respective polymer blend matrices, especially in the case of POM blend with $50 \mathrm{wt} \%$ of EOC17, testifying about synergetic modification of POM in respects to its thermal stability.

\section{CONCLUSIONS}

In the current research, the effects of two types of ethyleneoctene copolymers, differing with a-octene content (38\% for EOC 38 and $17 \%$ for EOC17), as well as zinc oxide ( $\mathrm{ZnO})$ on thermal behavior of polyoxymethylene (POM) are investigated. Results of thermogravimetric analysis show that, thermal resistance of POM can be increased by addition of either of the elastomers. The modifying effect of EOC17 in respect of thermal resistance is somewhat larger than that of EOC38 because the former contains smaller amount of labile tertiary carbon atoms in the macromolecule. Thermal stability of POM is efficiently improved also with addition of noncombustible $\mathrm{ZnO}$, allowing decrease gas exchange rate and facilitating inert gases, such as $\mathrm{CO}_{2}$, stay in the zone of thermal destruction. Simultaneous addition of EOC and $\mathrm{ZnO}$ to $\mathrm{POM}$ is synergistic with respect to thermal stability of the composite material.

\section{REFERENCES}

1. D. Feldman, J. Macromol. Sci., Pure Appl. Chem., 52, 648 (2015).

2. B. Forschler and C. Geiser, Kunststoffe Int., 10, 80 (2007).

3. K.J. Saunders, Organic Polymer Chemistry, Chapman \& Hall, London (1988).

4. J.R. Fried, Polymer Science and Technology, Englewood Cliffs, New Jersey (1995).

5. V.M. Archodoulaki, S. Luftl, and S. Seidler, Polym. Degrad. Stabil., 86, 75 (2004).

6. Y. Duan, H. Li, L. Ye, and X. Liu, J. Appl. Polym. Sci., 99, 3085 (2006).

7. L. Gan and L. Ye, J. Thermoplast. Compos. Mater., 23, 543 (2010).

8. Y. Hu, L. Ye, and X. Zhao, Polymer, 47, 2649 (2006).

9. N. Mantaranon, M. Kotaki, C.T. Lime, and S. Chirachanchai, RSC Adv., 94, 91468 (2016).

10. A.K. Das, S. Suin, N.K. Shrivastava, S. Maiti, J.K. Mishra, and B.B. Khatua, Polym. Compos., 35, 273 (2014).

11. T. Kongkhlang, Y. Kousaka, T. Umemura, D. Nakaya, W. Thuamthong, Y. Pattamamongkolchai, and S. Chirachanchai, Polymer, 49, 1676 (2008).

12. S. Wacharawichanant, P. Sahapaibounkit, and U. Saeueng, Adv. Mater. Res, 488-489, 82 (2012).

13. S. Wacharawichanant, S. Thongyai, A. Phutthaphan, and C. Eiamsamang, Polym. Test., 27, 971 (2008).

14. S. Wacharawichanant, A. Sangkhaphan, N. Sa-Nguanwong, V. Khamnonwat, S. Thongyai, and P. Praserthdam, J. Appl. Polym. Sci., 123, 3217 (2012).

15. T.R. Crompton, Thermo-Oxidative Degradation of Polymers, Smithers Rapra Technology, E-Book (2010).

16. J. Troitzsch, Plastics Flammability Handbook Principles, Regu-lations, Testing, and Approval, Hanser, Munich (2004). 